\title{
The prevalence and impact of Babesia canis and Theileria sp. in free-ranging grey wolf (Canis lupus) populations in Croatia
}

\author{
Ana Beck', Doroteja Huber ${ }^{1}$, Adam Polkinghorne ${ }^{2}$, Andrea Gudan Kurilj' ${ }^{1}$ Valerija Benko ${ }^{3}$, Vladimir Mrljak ${ }^{3}$,
} Slaven Reljić ${ }^{4}$, Josip Kusak ${ }^{4}$, Irena Reil ${ }^{5}$ and Relja Beck ${ }^{5^{*}}$

\begin{abstract}
Background: Babesia spp. and Theileria spp. are important emerging causes of disease in dogs. Alongside these domesticated hosts, there is increasing recognition that these piroplasms can also be found in a range of wild animals with isolated reports describing the presence of these pathogen in foxes (Vulpes vulpes) and captive grey wolves (Canis lupus). The prevalence and impact of these infections in free-ranging populations of canids are unknown. To gain a better insight into the epidemiology and pathogenesis of piroplasm infections in free-ranging grey wolves, pathological and molecular investigations into captive and free-ranging grey wolves in Croatia were performed.

Results: The carcasses of 107 free-ranging wolves and one captive wolf were the subjects of post-mortem investigations and sampling for molecular studies. A blood sample from one live captured wolf for telemetric tracking was also used for molecular analysis. PCR amplification targeting the 18S RNA gene revealed that 21 of 108 free-ranging wolves and one captive animal were positive for Theileria/Babesia DNA. Subsequent sequencing of a fragment of the 18S RNA gene revealed that 7/22 animals were positive for Babesia canis while the other amplified sequence were found to be identical with corresponding $18 \mathrm{~S}$ rDNA sequences of Theileria capreoli isolated from wild deer (15/22). Haematological and cytological analysis revealed the presence of signet-ring shaped or pear-shaped piroplasms in several animals with the overall parasite burden in all positive animals assessed to be very low. Pathological investigation of the captive animal revealed fatal septicemia as a likely outcome of hemolytic anaemia. There was little or no evidence of hemolytic disease consistent with babesiosis in other animals.
\end{abstract}

Conclusion: Importantly, the presence of $B$. canis in free-ranging grey wolves has not been described before but has been reported in a single fox and domestic dogs only. That $B$. canis infections cause disease in dogs but have little impact on wolf health possibly suggests that the wolf is the natural and the domestic dog is a secondary host. Surprisingly, the frequent finding of Theileria capreoli in wolves suggests that this Theileria species is not restricted to ungulates (cervids) but commonly infects also this carnivore species. Nevertheless, the potential role that these asymptomatically infected animals may play in the dispersal of these pathogens to susceptible sympatric species such as domesticated dogs requires further investigation.

Keywords: Grey wolf, Canis lupus, Croatia, Babesia canis, Theileria capreoli, Necropsy, Cytology, Histopathology, Genotyping

\footnotetext{
* Correspondence: relja.beck@gmail.com

${ }^{5}$ Department for Bacteriology and Parasitology, Croatian Veterinary Institute,

Zagreb, Savska cesta 143, 10000 Zagreb, Croatia

Full list of author information is available at the end of the article
} 


\section{Background}

Piroplasms are tick-borne haemoprotozoal parasites able to infect almost all mammalian species. The two main genera of piroplasms infecting wild and domestic animals are Babesia and Theileria, with both traditional morphological methods and more recent molecular methods leading to the discovery and (re-)classification of new species among these hosts [1-3]. A diverse range of wildlife species have now been described as hosts for these piroplasms including mammalian species such as lions, lynx, panthers, elephants, giraffes, antelope, buffalo, several deer species, raccoons, hyena, mongoose, rhinoceroses, and bird species such as seagulls and the kiwi $[4,5]$.

In Europe, two 'large' canine Babesia species, B. canis and $B$. vogeli, are the most frequently detected piroplasms in domestic dogs [1]. Two other 'small' canine piroplasms species, referred to as "Babesia vulpes", "Theileria annae" and Babesia cf. microti, and B. gibsoni, have been confirmed by molecular methods in dogs [6-8]. Non-canine species, B. caballi and T. equi, have been detected by PCR in symptomatic dogs in Spain and Croatia $[9,10]$. These piroplasm species have been documented in Croatian symptomatic and asymptomatic dogs [10], while "B. vulpes", "Theileria annae" and Theileria sp. have been confirmed in the Croatian population of free-ranging red foxes [11]. "Babesia vulpes" has also been molecularly confirmed in foxes from Spain, Hungary, Portugal, Italy and Bosnia and Herzegovina [12-17]. Unlike "B. vulpes", B. canis has been reported only in a single animal during a study of the fox population in Portugal [14] and in a single fox in a similar survey in Bosnia and Herzegovina [17].

Beyond the limited data supporting the presence of piroplasms in foxes, information on the presence and prevalence of piroplasms in other wild carnivores such as grey wolves (Canis lupus) is extremely limited. Two reports have described the presence and pathogenic potential of Babesia in captive grey wolves from Poland and Hungary $[18,19]$. In the former study, the diagnosis was based exclusively on clinical observations consistent with canine babesiosis (e.g. fever, splenomegaly, icterus, pigmenturia) that was resolved by imidocarb dipropionate treatment. Confirmatory diagnosis by detection of piroplasms in blood smear or molecular testing was not performed [18]. Erdelyi et al. [19] molecularly confirmed $B$. canis as a cause of death in two captive grey wolves suffering from the hemolytic disease. Another molecular epidemiological study conducted on an Italian freeranging grey wolf population failed to detect piroplasms in any of the seven animals investigated [12]. Larger scale studies are otherwise absent since the distribution of the grey wolf populations in Europe is highly fragmented and separated by human habitat.
The Croatian population of free-ranging wolves is increasing in number and spreading from the south Mediterranean and central mountainous habitats to more urban north-west lowland geographical regions of Croatia [20]. In the current study, we performed a molecular survey of piroplasmids in free-ranging grey wolves with the sympatric presence of Babesia canis-infected domesticated canids and Theileria sp. in cervids, respectively. This paper also reports two clinical and post-mortem cases of asymptomatic Babesia canis infection in two young-adult, free-ranging grey wolves and a fatal infection with $B$. canis in a captive grey wolf.

\section{Methods \\ Animals}

Wolves have been protected by Croatian law since 9 May 1995 [21]. According to the Wolf Management Plan for Croatia [21], all carcasses of wolves found must be submitted to the Faculty of Veterinary Medicine, Zagreb to determine the cause of death following postmortem analyses. The range of the Croatian population covers about $18,000 \mathrm{~km}^{2}$ of the mountainous and Mediterranean region of Croatia, which corresponds to $31.8 \%$ of the total Croatian territory [20]. In addition, the Croatian grey wolf can also be sporadically found in an additional $6,000 \mathrm{~km}^{2}$ area (transitional habitat) which corresponds to $10.6 \%$ of Croatian territory [20]. During the period of this study, the grey wolf population in Croatia was estimated to consist of 209 individual animals distributed in 50 packs, with a density of 1.7 wolves per $100 \mathrm{~km}^{2}$ [22].

For each free-ranging wolf investigated, GPS coordinates of each carcass found were determined and recorded on a map of Croatia (Additional file 1: Table S1; Fig. 1). They originated from four geographical regions: Gorski Kotar, Lika, Dalmatia and the aforementioned 'transitional habitat'. Gorski Kotar is a mountainous region with $63 \%$ of its surface covered by forest, mostly composed of deciduous and coniferous trees. The average altitude is $800 \mathrm{~m}$ with a moderate, rainy, continental climate zone [20]. Lika is a plateau in mountainous Croatia with similar forest cover and climatic conditions to Gorski Kotar [20]. Dalmatia is the southern part of Dinaric mountain range running from north-west to south-east. This region has a Mediterranean climate with vegetation mostly composed of bush, brush and evergreen plants. The transitional habitat is a region covered by deciduous forest and meadows with a moderate, continental climate [20].

A total of 108 free-ranging animals and one captive animal were investigated over a period of 20 years (1996-2015). Two out of 108 animals were found alive of which one was the animal (Wolf 109) held in captivity and was added to the study. A brief description of the 


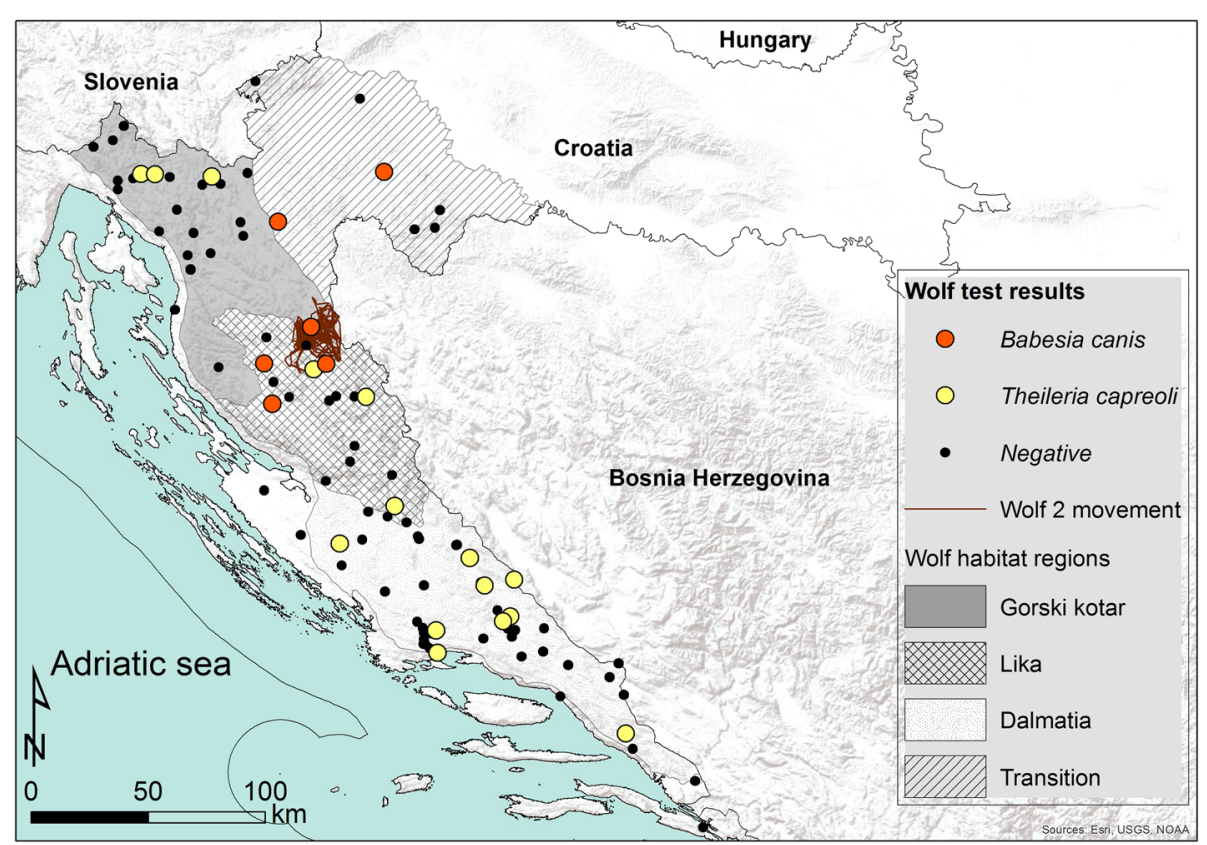

Fig. 1 Map of Croatia with marked positions of all investigated wolves with molecularly confirmed parasites (Background map was created using ArcGIS $^{\oplus}$ software by Esri. ArcGIS ${ }^{\oplus}$ and $\operatorname{ArcMap}^{\text {TM }}$ are the intellectual property of Esri and are used herein under license. Copyright $\odot$ Esri)

prospectively sampled animals (Wolf 2, Wolf 107, Wolf 109) follows:

Wolf 2: A male, 0.5 years old wolf was captured for telemetric research in Plitivička jezera national park, Lika region, Croatia, on 27 November 2014. The wolf was captured by live trap and immobilised with a combination of tiletamine hydrochloride and zolazepam hydrochloride (Zoletil 100@, Virbac, Virbac, Carros, France). During anesthesia, the animal was measured, equipped with a GPS tracking collar

(Vectronic $\odot$, Berlin, Germany) and blood-sampled from the cephalic vein for routine hematologic and biochemical analyses. After completing all measurements, the wolf was left in a secure and silent location in the woods prior to recovery. For the following 12 months, the wolf was satellite-tracked with location recording in six-hour intervals, until the collar was automatically dropped from the animal's neck.

Wolf 107: A male 1.5-year-old wolf was brought to the Clinic of Veterinary Faculty, Zagreb after a car collision outside of the city of Glina in the transitional habitat on 18 November 2015 for emergency surgery. During surgery, blood was sampled for routine haematology and biochemistry. After clinical examination, the spinal cord injury was estimated to be too severe for survival. The wolf was humanely euthanised and delivered for necropsy.

Wolf 109: A 17-year-old, male grey wolf born and kept in captivity in the Zagreb Zoo was delivered for necropsy on 26 May 2016. Seven months before death, the wolf was separated from the pack because of aggression towards other pack members, poor physical condition and poor sight. Three days before death, febrile disease with lethargy and anorexia was noted. Due to old age and the poor condition, the animal was humanely euthanised.

\section{Postmortem analysis}

Carcasses of 107 free-ranging wolves (including Wolf 107) and one captive wolf (Wolf 109) were delivered for necropsy regardless of the degree of autolysis. Body measurements and weight were determined and the age was estimated by teeth inspection using the teeth wear technique [23]. Tissue samples from 26 non-autolytic carcasses were submitted for further routine histopathology. Brain, kidney, liver, lung, myocardium and spleen slices were fixed in $10 \%$ neutral formalin, dehydrated, paraffin embedded, cut to a thickness of $5 \mu \mathrm{m}$ and stained with hematoxylin and eosin. Pieces of the brain, kidney, liver, lung, myocardium and spleen from each animal were frozen at $-20{ }^{\circ} \mathrm{C}$. Blood cloth, kidney, liver, myocardium, lung and spleen cut surface imprints were prepared, airdried and stained using the May-Grünwald-Giemsa protocol. Due to post-mortal hemolysis, the number of intracellular and extracellular piroplasms was evaluated in tissue imprints in approximately 4,000 erythrocytes and their surrounding areas per each slide. 


\section{Haematology and biochemistry}

Blood smears were prepared from EDTA-sampled blood from Wolf 2 and Wolf 107, air-dried and stained with May-Grünwald-Giemsa. Parasite burden was determined by counting of parasites visible in high power fields (HPF) containing a total number of 4,000 erythrocytes (10 HPF). Hematologic analyses were carried out using an automatic haematological counter (Horiba ABX@, Micros, France). Serum biochemistry was made by an automatic biochemical analyser (OLYMPUS AU 640®, Olympus Chemistry Analyzer, Hamburg, Germany) for the basic metabolic panel using referral intervals for wolves according to published values [24]. A blood aliquot was frozen at $-20{ }^{\circ} \mathrm{C}$ for molecular detection of pathogens.

\section{Molecular analysis}

Frozen blood from 2 wolves (Wolf 2 and Wolf 107) and spleen samples from all 106 free-ranging wolves and the captive wolf from Zagreb Zoo (Wolf 109) were processed by the same protocol. DNA was extracted from $20 \mu \mathrm{g}$ of tissue samples or $200 \mu \mathrm{l}$ of blood using the DNA Blood and tissue kit (Qiagen, Hilden, Germany) in the automatic extraction system Qiacube (Qiagen). In each round of extraction, one sample of DNase/RNaseFree distilled water was included as a blind control for DNA extraction. To detect members of the genera Babesia and Theileria, a fragment ( $560 \mathrm{bp})$ of the 18S rRNA gene was amplified and sequenced using the forward primer 5'-GTC TTG TAA TTG GAA TGA TGG-3' and the reverse primer $5^{\prime}$-CCA AAG ACT TTG ATT TCT CTC-3' [10]. After initial sequencing, a larger fragment of Theileria sp.-positive samples was re-amplified for the species conformation using a new set primers; forward 5'-AGT TTC TGA CCT ATC AG-3' and the reverse primer $5^{\prime}$-TTG CCT TAA ACT TCC TTG-3', that amplifies a $1,090 \mathrm{bp}$ fragment of the $18 \mathrm{~S}$ rRNA gene, as previously described [25]. Babesia-positive samples were further analysed with primers CRIPTOF 5'-AAC CTG GTT GAT CCT GCC AGT AGT CAT-3' and CRIPTOR 5'-GAA TGA TCC TTC CGC AGG TTC ACC TAC-3' that amplify complete $18 \mathrm{~S}$ rRNA gene under conditions described by Caccio et al. [26]. Same primer sets were used for sequencing. PCR reaction mixtures of $20 \mu \mathrm{l}$ were prepared to contain $10 \mu \mathrm{l} \mathrm{G2} \mathrm{GOTaq}$ master mix (Promega, Madison, WI, USA), 7.2 $\mu$ l of DNase/RNaseFree distilled water (Qiagen), $0.4 \mu \mathrm{l}$ of $10 \mathrm{pmol} / \mu \mathrm{l}$ each primer and $2 \mu \mathrm{l}$ of sample. The successful amplification of PCR product was confirmed by capillary electrophoresis QIAEXEL (Qiagen) using a QIAxcel DNA Fast Analysis kit, alignment markers (DNA QXAlignmentMarker15 bp/ $3 \mathrm{~kb}$ ) and QX DNA Size Marker 50-3,000 bp. Amplified PCR products were purified using EXOSAP-it ${ }^{\circ}$ USB $^{\circ}$ Products AffyInc., Ohio, USA) according to manufacturer's instructions and sequenced in both directions (Macrogen, Amsterdam, the Netherlands). The resulting sequences were assembled using the SeqMan Pro software, edited with Edit Seq tools in Lasergene (DNASTAR, Madison WI, USA) and compared with available sequences using BLAST in GenBank.

\section{Results \\ Pathological investigations of grey wolf carcasses}

In total, 107 free-ranging grey wolf carcasses were dissected with the cause of death determined primarily by gross findings for 100 of these animals (Additional file 1: Table S1). The most common cause of mortality was trauma, followed by organ rupture and exsanguination in 98 free-ranging animals. Lesions were caused by car or train collision or by gunshot. Rarely trauma was induced due to intraspecific strife. Two animals that died due to rabies had unremarkable gross findings with a mild to moderate degree of teeth destruction and foreign bodies in the stomach. In seven wolves, the cause of death remained undetermined due to severe decomposition postmortem. None of the dissected wolves showed signs of hemolytic disease.

Diffuse histiocytosis and mild erythrophagocytosis within the red pulp of the spleen were the single microscopic suggestions of hemolytic disease found in the wild Wolf 107, although round-shaped merozoites measuring $1.5 \mu \mathrm{m}$ were seen within a few erythrocytes in the capillaries of the brain (Fig. 2) and the myocardium. In the postmortem cytological imprints from blood clots, kidney, liver and lungs, round-shaped merozoites measuring approximately $1.7 \mu \mathrm{m}$ and rarely signet-ring shaped merozoites measuring $1.75 \mu \mathrm{m}$ (Fig. 3) were present. The parasite burden in all postmortem samples was very

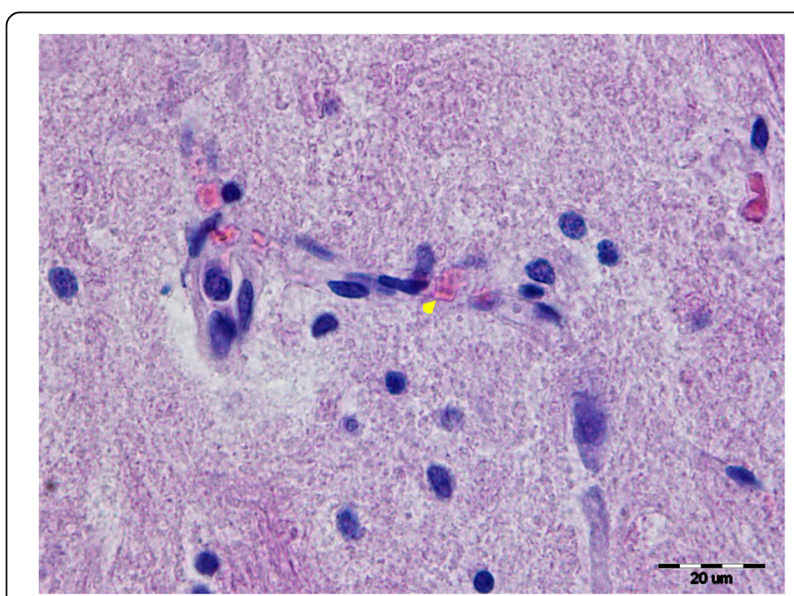

Fig. 2 Round merozoites of $B$. canis (arrowhead) within one erythrocyte in cerebellar capillary. Hematoxylin and eosin staining, 1000x magnification. Scale-bar: $20 \mu \mathrm{m}$ 


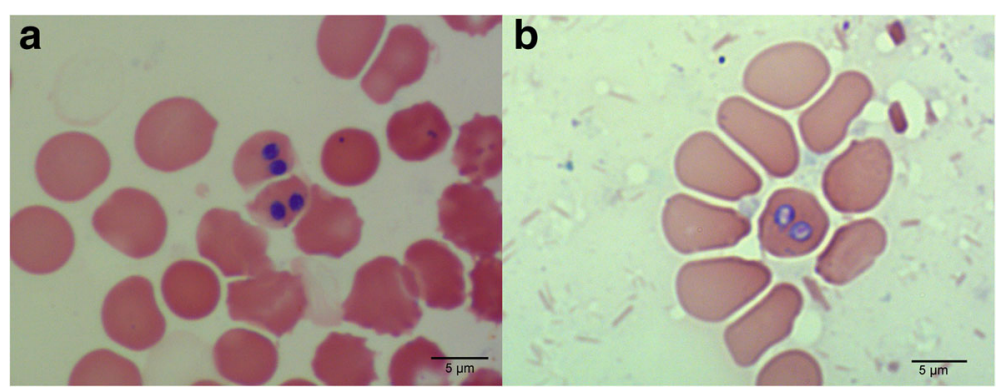

Fig. 3 a Round B. canis piroplasms within erythrocytes of a blood clot obtained at postmortem from Wolf 107. b Erythrocytes parasitized by ring-shaped piroplasms on lung tissue imprint from Wolf 107. May-Grünwald-Giemsa staining, 1000x magnification. Scale-bars: 5 um

low (approximately 20 piroplasms detected in 4,000 erythrocytes and their surrounding).

In cytological imprints from the kidneys, skeletal muscle and spleen from the captive wolf (Wolf 109), numerous round piroplasms measuring $1.7 \mu \mathrm{m}$ were evident within erythrocytes or in the background of the cytological sample (approximately 350 piroplasms). Necropsy of the captive wolf revealed pronounced jaundice of mucosa (Fig. 4a), eye sclera and subcutaneous tissue (Fig. 4b). In this case, the cause of death was multiple organ dysfunction syndromes leading to suffocation due to diffuse hemorrhagic lung oedema development. Hepatosplenomegaly (Fig. 4b) developed due to severe capillary network dilation and blood plasma stasis. Systemic hypoxia was accented by extensive intravascular and extravascular hemolysis. Thrombotic lesions connected with sepsis were found in the spleen in the form of occlusive fibrinous thrombosis of splenic artery segments leading to focally extensive ischemic infarctions. Consequences of myocardial, pulmonary and hepatic disseminated intravascular coagulation were seen by disseminated areas of coagulative necrosis and haemorrhage. Both kidneys had undergone massive acute cortical necrosis most likely due to severe prerenal hypoxia. Discoloration of tubular epithelial remnants and formation of intratubular luminal casts developed because of hemoglobinuria and bilirubinuria, also visible by the formation of bile plugs in the liver.

\section{Haematology and biochemistry}

Blood smears examined revealed signet-ring shaped or pear-shaped piroplasms within a few erythrocytes in Wolf 2 and Wolf 107. Signet-ring shaped piroplasms measured $2.1 \mu \mathrm{m}$ in diameter. Pear-shaped piroplasms measured $1.8 \mu \mathrm{m}$ in width and $4.4 \mu \mathrm{m}$ in length.

Wolf 2 showed a mild normochromic normocytic anemia $\left(4.3 \times 10^{12} / \mathrm{l}\right.$; reference values $\left.5.6-7.62 \times 10^{12} / \mathrm{l}\right)$, slight thrombocytopenia $\left(157 \times 10^{9} /\right.$; reference values $194-567 \times$ $\left.10^{9} / \mathrm{l}\right)$ and an increase in the plasma value of creatinine kinase (2,802 U/l; reference values 95-1,315 U/l). Traumatised Wolf 107 showed normochromic normocytic anaemia $\left(5.6 \times 10^{12} / \mathrm{l}\right.$; reference values $\left.6.36-8.19 \times 10^{12} / \mathrm{l}\right)$. The biochemical profile revealed that only the concentration of the enzyme creatinine kinase (3,577 U/l; reference values 95$1,315 \mathrm{U} / \mathrm{l})$ was elevated.

\section{Molecular detection of piroplasms}

In the current study, samples from 108 free-ranging grey wolves and one captive grey wolf were screened for the presence of Babesia/Theileria DNA. Out of 108 freeranging grey wolves, 21/108 (19.4\%) were positive for Babesia/Theileria spp. DNA. The captive Wolf 109 was also PCR positive for Babesia/Theileria spp. DNA.

Direct sequencing of the PCR products of these positive cases was used to determine the infecting piroplasm species. B. canis was detected in three animals that have

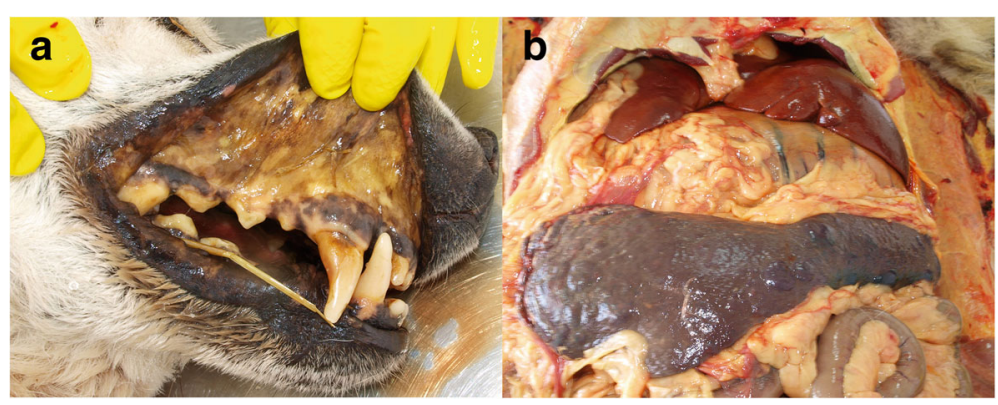

Fig. 4 a Yellow discoloration of oral mucosa in Wolf 109. b Hepatosplenomegaly and yellow discoloration of abdominal fat tissue in Wolf 109 
been studied in more detail in this investigation (Wolf 2, 107 and 109) as well as the carcasses of four freeranging wolves (Wolf 32, 49, 51 and 104). Amplified DNA fragments of around $550 \mathrm{bp}$ were found to represent an identical sequence which, following BLAST analysis, were identical to a $B$. canis isolate from a Croatian dog. Amplified fragments of 1,704 bp (GenBank accession number KY359360) from wolves 2, 107 and 109 were identical to isolate from a domestic dog from Croatia (AY072926). The remaining 15 PCR fragments of $550 \mathrm{bp}$ from free-ranging wolves were also sequenced and, after BLAST search found to be $100 \%$ similar to the $18 \mathrm{~S}$ rDNA sequence of two T. capreoli and the Theileria sp. 3185/02 isolate. For species confirmation, a larger fragment of 1,005 bp was successfully sequenced from six wolves, respectively, and deposited under accession number KY359359 in GenBank. All six sequences were identical to T. capreoli from wild Reeves' muntjac (KJ451470), T. capreoli from roe deer (AY726011), and the Theileria sp. 3185/02 isolate from red deer (AY421708).

Mapping of the obtained data revealed a diverse distribution of B. canis and T. capreoli (Fig. 1). The putative $T$. capreoli positive samples were from wolves in all studied areas except the transitional habitat while $B$. canis was present only in the Lika region at around $600 \mathrm{~m}$ above sea level and in two wolves from the transitional habitat. The highest prevalence of both piroplasm species was detected in Lika (28\%) with the transitional habitat having a similar prevalence $(28.5 \%)$, albeit the only detected species was $B$. canis (Table 1). During 12 months monitoring of movement activity, $B$. canis infected Wolf 2 covered area of $563 \mathrm{~km}^{2}$ (Fig. 1). The putative $T$. capreoli piroplasms were the only ones detected in Gorski Kotar and Dalmatia with a similar prevalence of 13.6 and $16.7 \%$, respectively (Table 1 ).

\section{Discussion}

One of the most important canine vector-borne diseases in Croatia is babesiosis caused mostly by $B$. canis [10]. Apart from domesticated dogs, B. canis has been molecularly confirmed in the neighbouring countries of Bosnia and Herzegovina from a single fox [17] and two captive grey wolves from Hungary [19] as well as in a single red fox (1/91) from Portugal [14]. Since data on Babesia infection in free-ranging carnivores are scarce, we performed a molecular and pathological investigation of Babesia and Theileria species infecting the freeranging population of wolves from Croatia to understand the prevalence, distribution and potential health impacts of these parasites on a wild canid population.

Molecular screening of free-ranging and captive grey wolves demonstrated that species of Theileria and Babesia could infect this host. To our knowledge, this study describes the first detection of $B$. canis in free-ranging wolves (5.5\%) and a captive animal from Croatia (Wolf 109). As expected, based on analysis of $18 \mathrm{~S}$ rRNA gene, the sequences were all identical to $B$. canis from Croatian dogs and similar to other European $B$. canis isolates [27, 28]. Interestingly, the prevalence of infected wolves from the Lika region and transitional habitat was almost identical. We were previously aware that the transitional habitat was endemic for $B$. canis infection in dogs [7], but the high prevalence in the more southern region of Lika was unexpected. The tick Dermacentor reticulatus, the only known vector of $B$. canis, was detected in wolves in the same region in 2009 (unpublished finding), fulfilling conditions for a continuous cycle of $B$. canis in wildlife and efficient spreading via infected ticks or infected animals [29]. A range of factors such as the ability of free-ranging wolves to cross a distance of several hundred kilometres [30] together with transovarial transmission of $B$. canis within $D$. reticulatus could facilitate the spread of the pathogen over long distances. This would appear to be confirmed in this study where Wolf 2 , infected with $B$. canis, originated from the Lika region but moved over a large area and during a 12-month period covered $563 \mathrm{~km}^{2}$. Young individuals leaving the pack and searching for new territories are another aspect of dispersing pathogens [21, 30]. Young, dispersing wolves in search for new habitat can frequently be observed in Croatia, including areas of sporadic occurrence as well as the urban north-west lowland geographic regions [20].

Except for Wolf 2 which was still alive at sampling, all free-ranging wolves infected with $B$. canis died due to trauma or rabies. Regarding the clinical impact, based on clinical assessments and post-mortem investigations in this study, it seems that free-ranging wolves can tolerate infection with $B$. canis, the most pathogenic piroplasm species for canines in Europe, without the

Table 1 Prevalence of infected free-ranging wolves from different geographical regions

\begin{tabular}{lllll}
\hline Region & No. of animals & Babesia canis \% $(95 \% \mathrm{Cl})$ & Theileria sp. \% (95\%Cl) & Total \% (95\% Cl) \\
\hline Gorski Kotar & 22 & 0 & $13.6(75.0-33.3)$ & $13.6(4.8-33.3)$ \\
Lika & 25 & $16.0(6.4-34.6)$ & $12.0(4.2-29.9)$ & $28.0(14.2-47.5)$ \\
Dalmatia & 54 & 0 & $16.7(9.0-28.7)$ & $16.7(9.0-28.7)$ \\
Transitional habitat & 7 & $28.5(8.2-64.1)$ & 0 & $28.5(8.2-64.1)$ \\
Total & 108 & $5.5(2.5-11.6)$ & $13.9(8.6-13.9)$ & $19.4(13.0-27.9)$ \\
\hline
\end{tabular}


development of clinical signs of severe haemolytic disease. Supporting this assumption is the absence of clinical, haematological and biochemical changes consistent with canine babesiosis in Wolves 2 and 107. Even though piroplasms were proven in blood smears of these infected wolves, only discrete normochromic normocytic anaemia, thrombocytopenia and slight elevation of creatinine kinase were confirmed. Traumatised Wolf 107 probably showed normochromic normocytic anaemia and creatinine kinase elevation due to internal and external blood loss and muscle and spinal cord tissue rupture. Although in Wolf 2, slight anaemia and thrombocytopenia could relate to $B$. canis infection, elevated levels of serum creatinine kinase were expected due to skeletal muscle fibre damage caused by capture in a live trap with subsequent leakage of creatinine kinase [31].

Although only a sample size of one, the monitoring carried out in the 12 months following the capture of Wolf 2 also suggests little or no impact on the movement of these otherwise healthy animals. In contrast to these findings in free-ranging animals, the captive wolf (109) infected with B. canis showed typical gross and microscopic lesions characteristic for canine babesiosis following post-mortem analysis. Infection with $B$. canis in dogs often results in a wide range of clinical presentations characterised by fever, lethargy, thrombocytopenia, anaemia, icterus, hemoglobinuria and multiple organ dysfunction syndromes with fatal outcome [32], consistent with postmortal findings of the captive wolf in this study. Although dogs can be asymptomatically infected, the number of such cases is very low [10]. It seems that free-ranging wild animals can tolerate Babesia infection better than their domesticated "relatives". This phenomenon has been described in cheetahs, and domestic cats, where cheetahs infected with Babesia lengau stay asymptomatic while infection in domestic cats progress and cause lethal cerebral babesiosis and haemolytic anaemia [33, 34]. The observation suggests that healthy, chronically infected wolves may act as reservoirs for $D$. reticulatus tick-mediated transmission to $B$. canis "free" regions and animals including domesticated dogs. A similar reservoir capacity was confirmed in experimental infection studies of young coyotes (Canis lantras) with B. gibsoni where animals were found harbouring parasites for several months without clinical signs [35].

Another piroplasm, suggested to be Theileria capreoli by $18 \mathrm{~S}$ rDNA sequence analysis, was an unexpected finding in the current study while also representing the first detection of this pathogen in grey wolves. The parasite was more frequently detected of the two piroplasms (13.9\%), and it appears that it was homogeneously distributed in all three regions except the transitional habitat. The $18 \mathrm{~S}$ rDNA sequences amplified in this study were identical to or similar to the sequence amplified from Theileria strains from red deer (3185/02; 100\% similarity, AY421708) and roe deer from Spain ( $T$. capreoli, 100\% similarity AY726011), a red fox (3185/02, 99.9\% similarity, HM212629) [11], red deer from Poland (ZS T04, 99.9\% similarity, DQ520836) [36], and a T. capreoli strain from a wild Reeves' muntjac from China (100\% similarity) [37]. Based on this study, it appears that $T$. capreoli or closely related Theileria sp. ZS T04, Theileria sp. 3185/02 can infect not only wild cervids but also wild canids such as red foxes and wolves. Theileria sp. 3185/02 was confirmed in roe deer and red deer from areas where two wolves were harbouring the same parasite (unpublished data). Detection of T. capreoli DNA in Ixodes ricinus ticks from Italy [38] raises the question whether this tick species may act as vectors for this Theileria species. In the current study, two Theileria-positive wolves from Gorski Kotar were found that share the same ecological niche with roe deer where $I$. ricinus was the only tick species detected [39]. Other infected wolves originated from mountainous areas where I. ricinus is the dominant tick species [40]. Further studies will be required to establish the possible role of $I$. ricinus as a vector for this piroplasm amongst different wildlife species.

Previous studies have shown that deer or roe deer are commonly infected with Theileria spp. without showing clinical signs [30]. Similarly, based on the observations made in this study on necropsied animals, no pathogenic effects of the putative $T$. capreoli infection (e.g. hemolytic disease) consistent with theilerosis was observed in free-ranging grey wolves. Our observations strongly suggest that the putative $T$. capreoli infections in free-ranging wolves are subclinical.

\section{Conclusions}

In the current study, we have found that the infection of free-ranging grey wolves with $B$. canis and Theileria capreoli is without clinical or pathological signs of babesiosis and/or theileriosis. Accordingly, our study revealed that a $B$. canis-infected wolf showed a large range of movement, which also highlights the potential 'risk' for these asymptomatically infected animals to be 'spillover' vectors of this pathogen into sympatric populations of domesticated dogs within their home-range. In contrast, a single Babesia canis infected captive animal did show symptoms of babesiosis. In this context, it should be mentioned that it has been described that piroplasmid-infected asymptomatic wild animals may die when suffering stressful situations (e.g. captivation). Finally, Theileria sp. has been detected in wolves that displayed identity with the $18 \mathrm{~S}$ rRNA gene fragment described of T. capreoli from different cervides. Our findings suggest a broader host specificity for $B$. canis as 
well as T. capreoli as previously assumed while the absence of pathology of piroplasmid infected free-ranging wolves suggests that this host species may be the natural host of the detected piroplasmid species.

\section{Additional file}

\section{Additional file 1: Table S1. Raw data for investigated wolves.} (XLSX $27 \mathrm{~kb})$

\section{Abbreviations}

Cl: confidence interval; GPS: Global positioning system; HPF: high power fields; PCR: polymerase chain reaction

\section{Acknowledgements \\ The authors thank Marko Poletto, DVM, for technical support.}

\section{Funding}

This research was funded by GENOTICKTRECK, Croatian Science Foundation Project number: 1957 and VetMedZg, an FP7 project of the European Commission. The field work was supported by Bernd Thies Foundation, "Plitvice Lakes" National Park, UK Wolf Conservation Trust, EURONATUR, Paradise Wildlife Park, "Sjeverni Velebit" National Park, "Velebit" Nature Park, Croatian State Institute for Nature Conservation and the Croatian Environmental Protection and Energy Efficiency Fund.

\section{Availability of data and materials}

The datasets supporting the conclusions of this article are included within the article and its additional file. Representative sequences for Theileria capreoliand Babesia canis are submitted to the GenBank database under accession numbers KY359359 and KY359360.

\section{Authors' contributions}

AB performed necropsies with sample collection, analyzed and interpreted gross, cytological and histological findings in necropsied wolves, and drafted the manuscript. DH performed necropsies with sample collection, analyzed and interpreted gross, cytologic and histological findings in necropsied wolves, performed DNA extractions and assisted with preparation of the manuscript. AP analyzed epidemiological and molecular data and assisted with drafting and editing of the manuscript. AGK performed necropsies with sample collection and the with figure preparations. VB performed hematological and biochemical analyses and data interpretation. VM performed hematological and biochemical analyses and data interpretation. JK completed fieldwork with sample collection, GPS tracking and figure preparation. SR fieldwork with sample collection. IR performed DNA extraction and molecular analyses. RB performed parasitological and genotyping analyses, epidemiological data analysis and interpretation, molecular screening and assisted with figure preparation, drafting and editing of the manuscript. All authors read and approved the final manuscript.

\section{Competing interests}

The authors declare that they have no competing interests.

\section{Consent for publication}

Not applicable.

\section{Ethics approval and consent to participate}

Autorization for wolf collection was provided by the Ministry of Environmental and Nature Protection, Zagreb, Croatia under class UP/I-61207/15-48/47 and number 517-07-1-1-1-15-4.

\section{Publisher's Note}

Springer Nature remains neutral with regard to jurisdictional claims in published maps and institutional affiliations.

\section{Author details}

${ }^{1}$ Department of Veterinary Pathology, Faculty of Veterinary Medicine, University of Zagreb, Vjekoslava Heinzela 55, 10000 Zagreb, Croatia. ${ }^{2}$ Centre for Animal Health Innovation, University of the Sunshine Coast, 90 Sippy Downs Drive, Sippy Downs, 4556 Brisbane, Australia. ${ }^{3}$ Internal Diseases Clinic, Faculty of Veterinary Medicine, University of Zagreb, Vjekoslava Heinzela 55, 10000 Zagreb, Croatia. ${ }^{4}$ Department of Biology, Faculty of Veterinary Medicine, University of Zagreb, Vjekoslava Heinzela 55, 10000 Zagreb, Croatia. ${ }^{5}$ Department for Bacteriology and Parasitology, Croatian Veterinary Institute, Zagreb, Savska cesta 143, 10000 Zagreb, Croatia.

Received: 17 August 2016 Accepted: 23 March 2017

Published online: 04 April 2017

\section{References}

1. Solano-Gallego L, Baneth G. Babesiosis in dogs and cats - expanding parasitological and clinical spectra. Vet Parasitol. 2011;181:48-60.

2. Schnittger $L$, Rodriguez A, Florin-Christensen M, Morrison D. Babesia: A world emerging. Infect Genet Evol. 2012;12:1788-809.

3. Alvardo-Rybak M, Solano-Gallego L, Milian J. A review of piroplasmid infections in wild carnivores worldwide: importance for domestic animal health and wildlife conservation. Parasit Vectors. 2016;9:538.

4. Penzhorn BL. Babesiosis of wild carnivores and ungulates. Vet Parasitol. 2006;138:11-21.

5. Mans B, Pienaar R, Latif A. Areview of Theileria diagnostics and epidemiology. Int J Parasitol Parasites Wildl. 2015;4:104-18.

6. Zahler M, Rinder H, Schein E, Goethe R. Detection of a new pathogenic Babesia microti-like species in dogs. Vet Parasitol. 2000;89:241-8.

7. Baneth G, Florin-Christensen M, Cardoso L, Schnittger L. Reclassification of Theileria annae as Babesia vulpes sp. nov. Parasit Vectors. 2015;8:207.

8. Hartelt K, Rieker T, Oehme RM, Brockmann SO, Muller W, Dorn N, et al. First evidence of Babesia gibsoni (Asian genotype) in dogs in Western Europe. Vector Borne Zoonotic Dis. 2007;7:163-6.

9. Criado-Fornelio A, Martinez-Marcos A, Buling-Sarana A, Barba-Carretero JC. Molecular studies on Babesia, Theileria and Hepatozoon in southern Europe Part I. Epizootiological aspects. Vet Parasitol. 2003;113:189-201.

10. Beck R, Vojta L, Mrljak V, Marinculić A, Beck A, Živičnjak T, et al. Diversity of Babesia and Theileria species in symptomatic and asymptomatic dogs in Croatia. Int J Parasitol. 2009;39:843-8.

11. Deždek D, Vojta L, Čurković S, Lipej Z, Mihaljević Ž, Cvetnić Ž, et al. Molecular detection of Theileria annae and Hepatozoon canis in foxes (Vulpes vulpes) in Croatia. Vet Parasitol. 2010;172:333-6.

12. Zanet S, Trisciuoglio A, Bottero E, de Mera IG F, Gortazar C, Carpignano MG, et al. Piroplasmosis in wildlife: Babesia and Theileria affecting free-ranging ungulates and carnivores in the Italian Alps. Parasit Vectors. 2014;7:70.

13. Farkas R, Takács N, Hornyák Á, Nachum-Biala Y, Hornok S, Baneth G. First report on Babesia cf. microti infection of red foxes (Vulpes vulpes) from Hungary. Parasit Vectors. 2015:8:55.

14. Cardoso L, Cortes HCE, Reis A, Rodrigues P, Simões M, Lopes AP, et al. Prevalence of Babesia microti-like infection in red foxes (Vulpes vulpes) from Portugal. Vet Parasitol. 2013;196:90-5.

15. Barandika JF, Espí A, Oporto B, Del Cerro A, Barral M, Povedano I, et al. Occurrence and genetic diversity of piroplasms and other Apicomplexa in wild carnivores. Parasitology. 2016;2:1-7.

16. Millán J, Proboste T, de Mera IGF, Chirife AD, de la Fuente J, Altet L. Molecular detection of vector-borne pathogens in wild and domestic carnivores and their ticks at the human-wildlife interface. Ticks Tick Borne Dis. 2016;7:284-90.

17. Hodžić A, Alić A, Fuehrer H-P, Harl J, Wille-Piazzai W, Duscher GG. A molecular survey of vector-borne pathogens in red foxes (Vulpes vulpes) from Bosnia and Herzegovina. Parasit Vectors. 2015;8:88.

18. Karbowiak G, Hapunik J, Miniuk M. The case of babesiosis in farmed wolf (Canis lupus L). Wiad Parazytol. 2008;54:243.

19. Erdelyi K, Mezosi L, Vladov S, Foldvari G. Fatal acute babesiosis in captive grey wolves (Canis lupus) due to Babesia canis. Ticks Tick Borne Dis. 2013;5:281-3.

20. Jeremić J, Desnica S, Štrbenac A, Hamidović D, Huber Đ, Kusak J. Report on the state of the wolf population in Croatia in 2014. Zagreb: Technical report of Croatian State Institute for Nature Protection; 2014. doi:10.13140/2. 1.4560.2884.

21. Štrbenac A, Kusak J, Huber $Đ$, Jeremić J, Oković P, Majić-Skrbinšek A, et al. Wolf management plan for Croatia for period from 2010 to 2015. Zagreb: Croatian State Institute for Nature Protection; 2010. ISBN 978-953-7169-82-4. 
22. Kusak J, Skrbinšek AM, Huber D. Home ranges, movements, and activity of wolves (Canis lupus) in the Dalmatian part of Dinarids, Croatia. Eur J Wildl Res. 2005;51:254-62.

23. Landon DB, Waite CA, Peterson RO, Mech LD. Evaluation of age determination techniques for gray wolves. J Wildl Manag. 1998;62:674-82.

24. Thorensen Sl, Arnemo JM, Liberg O. Hematology and serum clinical chemistry reference intervals for free-ranging Scandinavian gray wolves (Canis lupus). Vet Clin Pathol. 2009;38:224-9.

25. Allsopp BA, Baylis HA, Allsopp MT, Cavalier-Smith T, Bishop RP, Carrington DM, et al. Discrimination between six species of Theileria using oligonucleotide probes which detect small subunit ribosomal RNA sequences. Parasitology. 1993;107:157-65.

26. Caccio SM, Antunovic B, Moretti A, Mangili V, Marinculic A. Rafaj RB, et a Molecular characterisation of Babesia canis canis and Babesia canis vogeli from naturally infected European dogs. Vet Parasitol. 2002;106:285-92.

27. Schaarschmidt D, Gilli U, Gottstein B, Marreros N, Kuhnert P, Daeppen JA, et al. Questing Dermacentor reticulatus harbouring Babesia canis DNA associated with outbreaks of canine babesiosis in the Swiss Midlands. Ticks Tick Borne Dis. 2013;4:334-40.

28. Ionita M, Mitrea IL, Pfister K, Hamel D, Buzatu CM, Silaghi C. Canine babesiosis in Romania due to Babesia canis and Babesia vogeli: a molecular approach. Parasitol Res. 2012;110:1659-64.

29. Földvári G, Široký P, Szekeres S, Majoros G, Sprong H. Dermacentor reticulatus: a vector on the rise. Parasit Vectors. 2016;9:314.

30. Kaczensky P, Chapron G, von Arx M, Huber $Đ$, Andrén H, Linnell J. Status, management and distribution of large carnivores - bear, lynx, wolf \& wolverine - in Europe. Part 1- Europe summaries. Report: 1-72. A Large Carnivore Initiative for Europe Report prepared for the European Commission. 2013. http://ec.europa.eu/environment/nature/conservation/ species/carnivores/pdf/task_1_part2_species_country_reports.

31. Huber $Đ$, Kusak J, Žvorc Z, Rafaj RB. Effects of sex, age, capturing method, and season on serum chemistry values of brown bears in Croatia. J Wildl Dis. 1997;33:790-4

32. Matijatko V, Kiš I, Torti M, Brkljačić M, Kučer N, Rafaj RB, et al. Septic shock in canine babesiosis. Vet Parasitol. 2009;162:263-70.

33. Bosman AM, Oosthuizen EC, Peirce MA, Venter EH, Penzhorn BL. Babesia lengau sp. nov., a novel Babesia species in cheetah (Acinonyx jubatus, Schreber, 1775) populations in South Africa. J Clin Microbiol. 2010;48:2703-8.

34. Bosman AM, Oosthuizen MC, Venter EH, Steyl JC, Gous TA, Penzhorn BL. Babesia lengau associated with cerebral and haemolytic babesiosis in two domestic cats. Parasit Vectors. 2013;6:128.

35. Evers HV, Kocan AA, Reichard MV, Meinkot JH. Experimental Babesia gibsoni infection in coyotes (Canis latrans). J Wild Dis. 2003;39:904-8.

36. Sawczuk M, Maciejewska A, Skotarczak B. Identification and molecular characterization of Theileria sp. infecting red deer (Cervus elaphus) in northwestern Poland. Eur J Wildl Res. 2008;54:225-30

37. Li Y, Ze C, Zhijie L, Junlong L, Jifei Y, Qian L, et al. Molecular identification of Theileria parasites of northwestern Chinese Cenvidae. Parasit Vectors. 2014;147:225.

38. Galuppi R, Aureli S, Bonoli C, Caffara M, Tampieri MP. Detection and molecular characterization of Theileria sp. in fallow deer (Dama dama) and ticks from an Italian natural preserve. Res Vet Sci. 2011;91:110-5.

39. Pintur K, Beck R, Babić I, Popović N, Florijančić T, Krapinec K, et al. Tick infestation in roe deer from Gorski Kotar area, Croatia. Proceedings of the 47th Croatian and 7th International Symposium on Agriculture; 2012. ISBN 978-953-7878-05-4

40. Krčmar S. Hard ticks (Acari, Ixodidae) of Croatia. ZooKeys. 2012;234:19-57.

\section{Submit your next manuscript to BioMed Central and we will help you at every step:}

- We accept pre-submission inquiries

- Our selector tool helps you to find the most relevant journal

- We provide round the clock customer support

- Convenient online submission

- Thorough peer review

- Inclusion in PubMed and all major indexing services

- Maximum visibility for your research

Submit your manuscript at www.biomedcentral.com/submit
Biomed Central 